\title{
Da esclerodermia ao síndrome de poems
}

\section{From scleroderma to poems syndrome}

Palavras-chave: POEMS, esclerodermia Key-words: POEMS, scleroderma

Homem, 84 anos, com antecedentes de hipotiroidismo e alterações cutâneas recentes compatíveis com esclerodermia , confirmadas em biópsia cutânea, mas com estudo auto-imune negativo. Foi internado por queixas constitucionais. Ao exame objetivo, apresentava-se emagrecido, com lesões de vitiligo nas mãos além das de esclerodermia (figura 1) e distensão abdominal com ascite (figura 2). Com a hipótese de a esclerodermia constituir uma manifestação paraneoplásica, foi submetido a estudo alargado, orientado para despiste de neoplasia oculta. Todo o estudo analítico, imagiológico e endoscópico foi inconclusivo, com excepção da identificação de um pico monoclonal lgG/Kappa, mas sem reunir critérios para diagnóstico de mieloma múltiplo. Cinco meses mais tarde foi reinternado por agravamento do estado geral, paraparésia e hipoestesia progressivas dos membros inferiores. Efectuou electromiografia que revelou polineuropatia sensitivo-motora. Estas manifestações - polineuropatia axonal sensitivo-motora grave simétrica dos membros inferiores, esclerodermia, gamapatia monoclonal IgG/Kappa, hipotiroidismo, ascite - foram então enquadradas em Síndrome de POEMS ${ }^{1,2}$. Iniciou corticoterapia em dose imunossupressora mas com evolução desfavorável, falecendo ainda no internamento. A variedade de manifestações com que a Síndrome de POEMS se apresenta, pode conduzir a diversos diagnósticos diferenciais ${ }^{3}$. Para a sua suspeição é essencial a realização de uma história clínica e exame objetivo cuidados, assim como uma revisão minuciosa de todos os achados dos exames complementares ${ }^{3}$. Este caso enfatiza a necessidade de considerar o diagnóstico diferencial de síndrome de POEMS num doente com alterações de tecido conjuntivo e pico monoclonal identificado $0^{4,5}$.

\section{Bibliografia}

1. Dispenzien, Angela, POEMS Syndrome, Society of Hematology, 2005, 360-367

2. Angela Dispenzieri, Robert A. Kyle, Martha Q. Lacy, S. Vincent Rajkumar, Terry M. Therneau, Dirk R. Larson, et al, POEMS syndrome: definitions and long-term outcome, Blood, April 2003, Volume 101, Number 7

3. Gachoka DN, Prince G, POEMS syndrome - A case report revealing a complex evolving diagnosis, Clinical Case Report, 2015; 3(1): 60-63

4. Eidner T. Oelzner P., Ebhardt H., Kosmehl H., Stein G., Hein G, Clinical manifestation of POEMS syndrome with features of connective tissue disease, Clin Rheumatol. $2001 ; 20(1): 70-2$

5. Hasegawa M, Orito H, Yamamoto K, Hamaguchi Y, Fugimoto M, Takehara K, Skin Sclerosis as a manifestation of POEMS syndrome, J Dermatol. 2012 Nov;39(11):922-6

\section{Diagnóstico: Síndrome de POEMS}

\section{A.S. Montez ${ }^{1}$, E. Rocha ${ }^{2}$}

- Interna de Formação Específica de Medicina Interna do Centro Hospitalar do Baixo Vouga, EPE ${ }^{2}$ Assistente Hospitalar de Medicina Interna do Centro Hospitalar do Baixo, EPE
Figura 1. Vitiligo em ambas as mãos. Lesões de esclerodermia dispersas por todo o corpo, com predomínio na região dorsal, abdominal e membros.
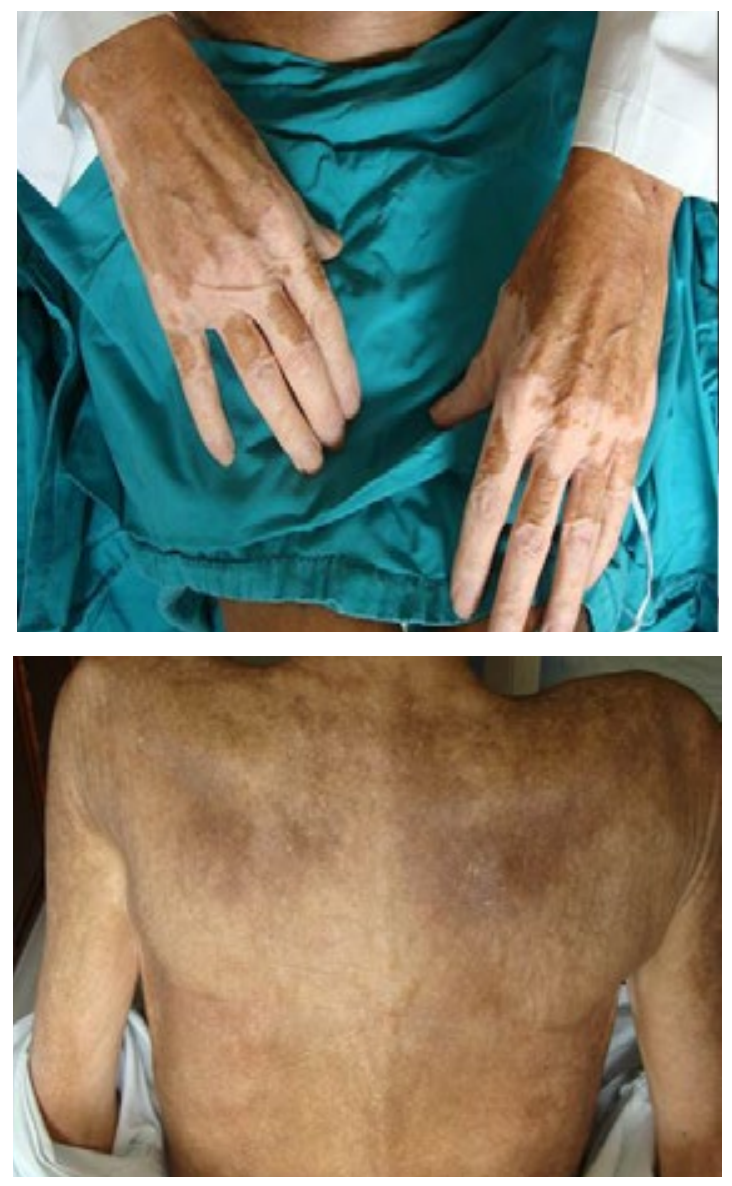

Figura 2. Abdomen distendido, por ascite. Lesões de esclerodermia abdominais.

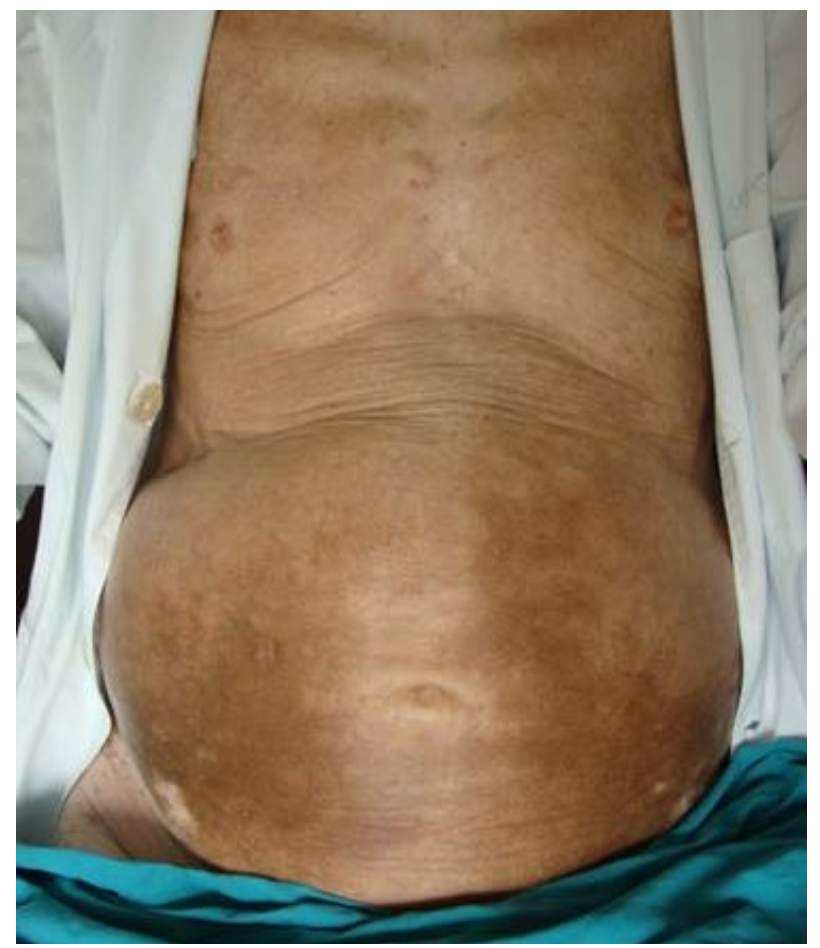

